\title{
Sintesis dan Karakterisasi Komposit Alginat/Zeolit/Fe-Zn Sebagai Salah Satu Material Pupuk Penyimpan Fe dan Zn
}

\author{
Muhammad Arsyik Kurniawan *, Indah R. Wahyuningrum, Dela Anggraini \\ Program Studi Kimia, Universitas Islam Indonesia, Jalan Kaliurang KM 14,5 Sleman \\ Yogyakarta Indonesia 55584 \\ *e-mail: m.arsyik@uii.ac.id
}

\begin{abstract}
ABSTRAK
Telah dilakukan penelitian material komposit dalam bentuk penyimpanan unsur kimia berupa nutrisi/pupuk dalam bidang agricultural. Komposit ramah lingkungan, murah serta mudah didapat ini dibuat dari campuran alginat dan zeolit. Komposit disintesis dengan komposisi alginat/zeolit (1:1) dan variasi kation Fe, Zn dan Fe-Zn. Penelitian ditujukan untuk mengetahui karakter komposit alginat/zeolit yang terembankan kation Fe dan Zn didalamnya, karakterisasi dilakukan baik secara visual fisik dan molekular menggunakan analisis spetrofotometer inframerah. Hasil penelitian diperoleh berupa komposit tekstur dan warna visual yang berbeda-beda sesuai dengan jenis kation yang diemban, komposisi sampel yang dihasilkan dapat dijadikan dasar pengembangan material komposit berbasis material alginat/zeolit untuk mensuplai nutrisi bagi tanaman berupa unsur hara mikronutrien seperti Fe dan $\mathrm{Zn}$.
\end{abstract}

Kata Kunci : Alginat, Zeolit, Fe, Zn, Pupuk

\begin{abstract}
Composite materials have been studied in the form of storage of chemical elements as fertilizers in the field of agriculture. Composites are environmentally friendly, cheap and easily obtainable is made from a mixture of alginate and zeolite. The composites are synthesized with alginate/zeolite composition (1:1) and variations of $\mathrm{Fe}, \mathrm{Zn}$, and $\mathrm{Fe}-\mathrm{Zn}$. Research is held with the aim to find out the character of alginate/zeolite composite loaded by $\mathrm{Fe}$ and $\mathrm{Zn}$ cations, the characterization was done both physically and molecularly by using an infrared spectrophotometer. The results were obtained in the form of composite fertilizer that has visual textures and colors that vary according to the type of cation carried. The composition of the resulting sample can be used as the basis for developing of composite materials based on alginate material/zeolite to supply nutrients to the plants in the form of nutrients micronutrients such as Fe and $\mathrm{Zn}$.
\end{abstract}

Keywords: Alginate, Zeolite, Fe, Zn, Fertilizer

\section{Pendahuluan}

Unsur hara sangat penting diperlukan

bagi tanaman dalam pertumbuhan,

pembentukan jaringan dan kegiatan hidup lainnya, biasanya unsur hara tersebut diperoleh dari tanah. Unsur penting yang dibutuhkan tanaman diantaranya unsur Fe (besi) dan $\mathrm{Zn}$ (seng). Unsur Fe berguna 
dalam metabolisme bagi tanaman, diantaranya dalam pembentukkan akar (Morrissey and Guerinot, 2009) dan sangat berperan dalam banyak proses fisiologis tanaman (Hochmuth, 2011). Sedangkan Zn berperan sebagai fungsional, struktural dan regulator kofaktor enzim, kekurangan $\mathrm{Zn}$ dapat mengakibatkan gangguan aktifitas enzimatik (Cakmak et al., 1999).

Penelitian mengenai modifikasi dan pengembangan pupuk telah banyak dikembangkan baik menggunakan bahan konvensional maupun modern. Pupuk konvensional saat ini banyak tersebar dalam berbagai bentuk seperti granular dan cairan. Namun pupuk konvensional dapat membahayakan bagi lingkungan terutama bila digunakan berlebihan, dapat membakar tanaman dan mencemari perairan. (Savci, 2012) Salah satu teknik pupuk modern adalah menggunakan material pengemban (unsur hara) yang ramah lingkungan yakni Na-alginat dan zeolit. Alginat adalah suatu polisakarida yang diekstrak dari bahan alga coklat dan terdiri atas dua unit struktur, yaitu guluronat (G) dan mannuronat (M). Guluronat dan mannuronat membentuk berbagai konformasi dalam struktur polimer alginat, di antaranya G-M, M-M, dan G-G (Draget and Taylor, 2011). Zeolit adalah mineral alam yang tersusun dari aluminosilikat terhidrasi yang memiliki pori dan berstruktur tiga dimensi (Tsintskaladze et al., 2016). Dengan ketersediaan yang melimpah di alam dan memiliki sifat mengikat kation, maka Naalginat dan zeolit dapat digunakan sebagai bahan material pupuk penyimpan unsur Fe dan Zn.

\section{Tujuan Penelitian}

Tujuan penelitian ini adalah sintesis, karakterisasi visual secara fisik dan kimia melalui analisis gugus fungsi menggunakan spektrofotometer inframerah.

\section{Metode Penelitian}

\section{Alat}

Peralatan yang digunakan diantaranya peralatan gelas lab, kaca arloji, pompa peristaltik, $\mathrm{pH}$ indikator universal, , neraca analitik, oven, penggojok, spektrofotometer inframerah (PerkinElmer).

Bahan-bahan yang digunakan dalam penelitian ini adalah zeolit alam dari Klaten, Na-alginat, serta bahan-bahan kimia produksi Merck dengan kemurnian analisis meliputi, Besi (III) Klorida 
$\left(\mathrm{FeCl}_{3} \cdot 6 \mathrm{H}_{2} \mathrm{O}\right)$, Seng (II) Klorida $\left(\mathrm{ZnCl}_{2} \cdot 2 \mathrm{H}_{2} \mathrm{O}\right)$ dan akuades.

\section{Prosedur penelitian}

\section{Sintesis komposit alginat/zeolit/Fe-Zn} $(1: 1)$

Sebanyak 2 g Na-alginat dilarutkan dalam $100 \mathrm{~mL}$, di wadah lain sebanyak $2 \mathrm{~g}$ zeolit alam didispersikan dalam $100 \mathrm{~mL}$ akuades. Kemudian keduanya dicampur dan diaduk hingga homogen.

Campuran Na-alginat dan zeolit alam dibentuk menjadi bulatan dengan cara diteteskan kedalam 3 wadah berisi $200 \mathrm{~mL}$ masing-masing $\mathrm{Fe}, \mathrm{Zn}$ dan $\mathrm{Fe}-\mathrm{Zn}$ 0,1 M dengan menggunakan pompa peristaltik, dan direndam selama 24 jam.

Setelah direndam selama 24 jam, komposit disaring dan dicuci dengan akuades hingga filtrat hasil cucian memiliki pH 6-7. Komposit kemudian dikeringkan dalam oven pada suhu $\pm 60^{\circ}$ C.

Uji visual fisik

Uji ini dilakukan dengan pengamatan analisis terhadap warna dan bentuk fisik komposit alginat/zeolit/Fe-Zn)

\section{Uji kualitatif spektrofotometer FT-IR}

Uji ini dilakukan untuk mengetahui gugus-gugus fungsi dari alginat dan zeolit memiliki situs aktif yang berpotensi untuk mengikat Fe(III) dan $\mathrm{Zn}(\mathrm{II})$.

\section{Hasil dan Pembahasan}

Berdasarkan hasil uji visual didapatkan bentuk bulatan (beads) seperti terlihat pada Gambar 1.
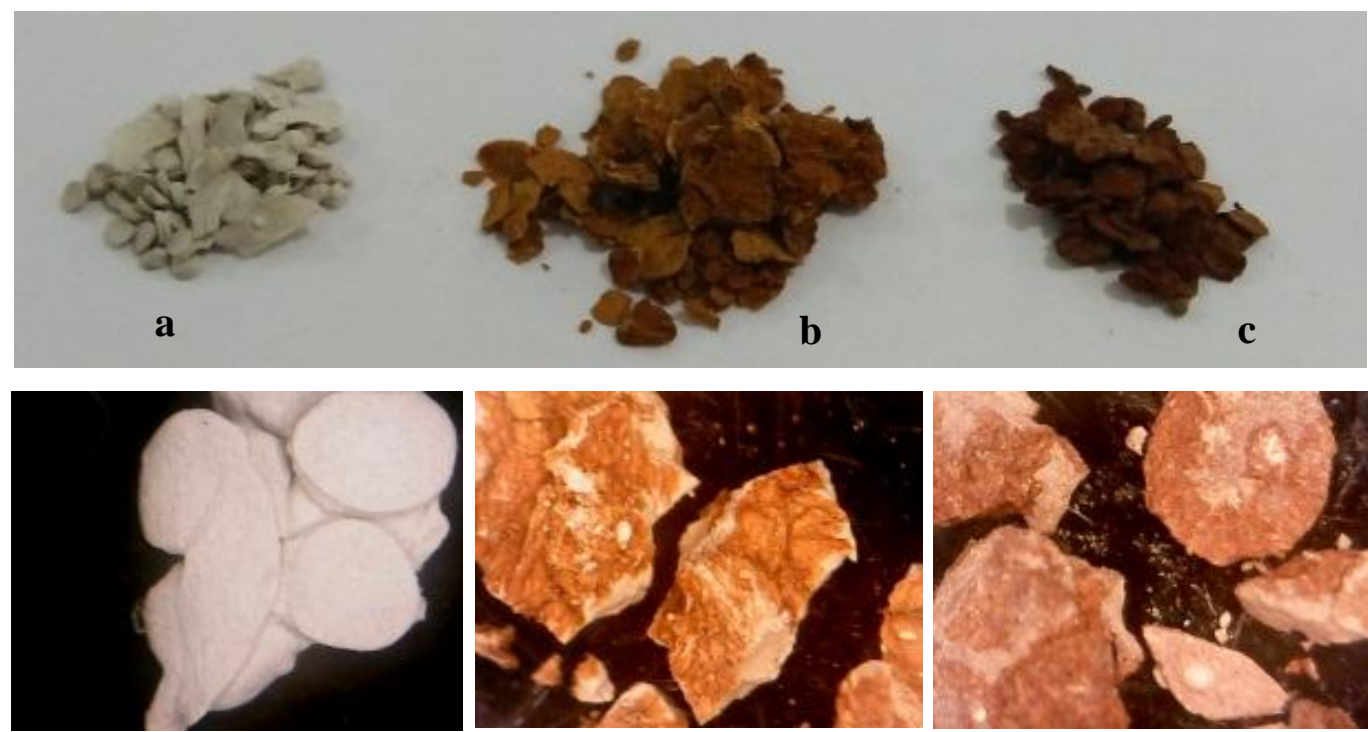

Gambar 1. Karakter visual komposit alginat/zeolit dengan kation Zn (a), Fe-Zn (b) dan $\mathrm{Fe}(\mathrm{c})$. 
Komposit ini dibentuk dari alginat dan zeolit dengan perbandingan 1:1. Secara visual komposit yang dihasilkan memiliki granul yang tidak sempurna bulat, melainkan seperti kepingan. Warna komposit yang berbeda-beda dipengaruhi oleh senyawa kompleks yang terbentuk antara gugus-gugus aktif didalamnya. Komposit 1a berwarna putih diperkirakan terbentuk partikel $\mathrm{ZnO}$ (Völz et al., 2000). Komposit 1c memiliki warna merah bata diperkirakan terbentuk kompleks $\mathrm{Fe}_{2} \mathrm{O}_{3}$ (Ali et al., 2016), dan pada komposit 1c memiliki warna diantara putih dan merah (jingga), diperkirakan terbentuk dari gabungan dua jenis kompleks $\mathrm{ZnO}$ dan $\mathrm{Fe}_{2} \mathrm{O}_{3}$.

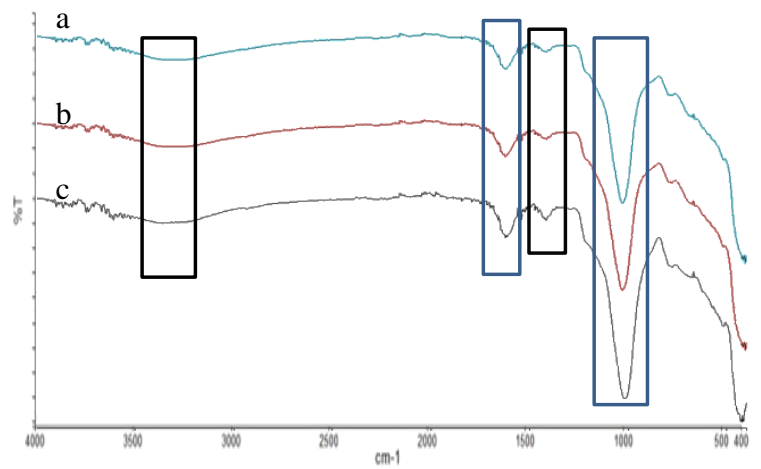

Gambar 2. Perbandingan spektra IR komposit alginat/zeolit/, $\mathrm{Fe}(\mathrm{a}), \mathrm{Fe}-\mathrm{Zn}(\mathrm{b}), \mathrm{Zn}(\mathrm{c})$

Perbedaan warna yang tampak pada komposit didominasi oleh interaksi kompleks kation $\mathrm{Fe}$ dan $\mathrm{Zn}$ dengan kombinasi alginat/zeolit didalam komposit. Hal ini didukung dengan pengamatan menggunakan spektrofotometer inframerah dimana gugus fungsi yang muncul didominasi dari gugus fungsi yang terdapat pada senyawa alginat dan zeolit. Hal ini dapat dilihat pada Gambar 2.

Spektra inframerah dari semua komposit memperlihatkan gugus fungsi yang dimiliki oleh alginat yang memperlihatkan puncak serapan pada bilangan di wilayah gelombang 3362,96$3308,97 \mathrm{~cm}^{-1} ; 1622,57-1622,32 \mathrm{~cm}^{-1}$; $1415,60-1415,89 \mathrm{~cm}^{-1}$; dan 1017,42$1028,23 \mathrm{~cm}^{-1}$. Puncak-puncak tersebut menginterpretasikan ikatan yang terdapat pada struktur alginat yang sesuai dengan referensi di antaranya, uluran vibrasi ikatan O-H pada puncak serapan 3450,40 $\mathrm{cm}^{-1}$, uluran asimetris $\mathrm{COO}^{-}$pada bilangan gelombang $1611,34 \mathrm{~cm}^{-1}$, uluran simetris $\mathrm{COO}^{-}$pada bilangan gelombang 1440,23 $\mathrm{cm}^{-1}$, vibrasi $-\mathrm{C}-\mathrm{O}$ dari kelompok eter pada $1043,52 \mathrm{~cm}^{-1}$ (Nayak and Sahoo, 2011).

Spektra inframerah komposit juga memperlihatkan gugus fungsi yang dimiliki oleh zeolit yang memperlihatkan puncak serapan pada bilangan di wilayah gelombang 3362,96-3308,97 $\mathrm{cm}^{-1}$; $1622,57-1622,32 \mathrm{~cm}^{-1}$; dan 1017,42- 
$1028,23 \mathrm{~cm}^{-1}$. Puncak-puncak tersebut menginterpretasikan ikatan pada struktur zeolit yang sesuai dengan referensi di antaranya, uluran vibrasi ikatan $\mathrm{O}-\mathrm{H}$ pada puncak serapan $3400-3260 \mathrm{~cm}^{-1}$, vibrasi tekukan $\mathrm{H}-\mathrm{O}-\mathrm{H}$ pada bilangan gelombang 1611,34 $\mathrm{cm}^{-1}$, vibrasi eksternal dan asimetris $\quad \mathrm{TO}_{4} \quad(\mathrm{~T}=\mathrm{Si}, \mathrm{Al}) \quad$ pada $990-1190 \mathrm{~cm}^{-1}$ (Pechar and Rykl, 1981). Dapat disimpulkan bahwa spektra inframerah alginat dan zeolit didalam komposit saling tumpang tindih di wilayah yang sama. Perbandingan data inframerah dapat dilihat di Tabel 1.

Tabel 1. Spektra serapan gugus fungsi berbagai komposit dibandingkan dengan referensi

\begin{tabular}{|c|c|c|c|c|c|c|}
\hline \multicolumn{3}{|c|}{ Komposit alginat/zeolit/... } & \multirow{2}{*}{ Ref a } & \multirow{2}{*}{$\begin{array}{l}\text { Gugus Fungsi } \\
\text { Alginat }\end{array}$} & \multirow{2}{*}{ Ref $b$} & \multirow{2}{*}{$\begin{array}{c}\text { Gugus } \\
\text { Fungsi } \\
\text { Zeolit }\end{array}$} \\
\hline $\mathrm{Fe} / \mathrm{cm}^{-1}$ & $\mathrm{Zn} / \mathrm{cm}^{-1}$ & $\mathrm{Fe}-\mathrm{Zn} / \mathrm{cm}^{-1}$ & & & & \\
\hline 3362,96 & 3362,47 & 3308,97 & 3450,40 & $\mathrm{O}-\mathrm{H}$ & $3400-3260$ & $\mathrm{O}-\mathrm{H}$ \\
\hline 1622,07 & 1622,32 & 1622,57 & 1611,34 & $\begin{array}{c}\text { asimetris } \\
\mathrm{COO}^{-}\end{array}$ & $1630-1640$ & $\mathrm{H}-\mathrm{O}-\mathrm{H}$ \\
\hline 1415,60 & 1415,89 & 1415,85 & 1440,23 & simetris $\mathrm{COO}^{-}$ & & \\
\hline 1027,76 & 1017,42 & 1028,23 & 1043,52 & $\mathrm{C}-\mathrm{O}$ eter & $990-1190$ & Al-O, Si-O \\
\hline
\end{tabular}

Ref a (Nayak and Sahoo, 2011), Ref b (Pechar and Rykl, 1981)

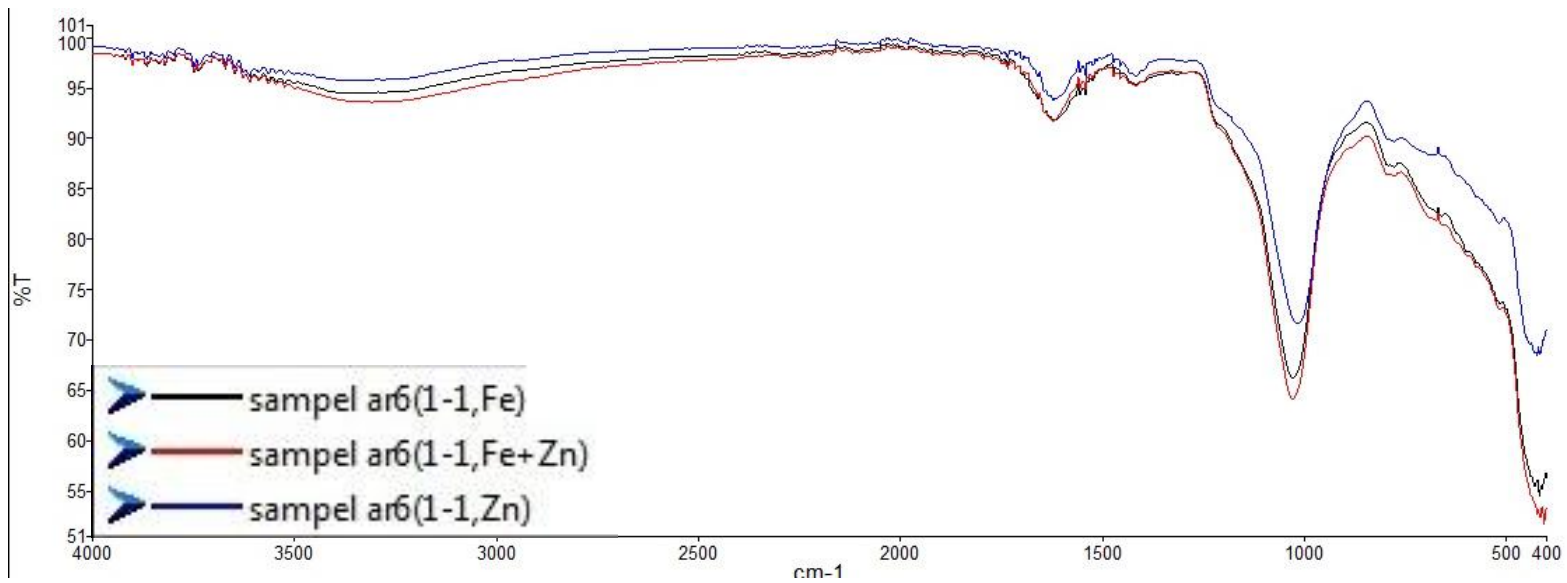

Gambar 3. Perbandingan spektra berdasarkan besar intesitas serapan dari komposit alginat/zeolit/, Fe(hitam), Fe-Zn(merah), Zn(biru)

Gambar 3 menampilkan grafik perbandingan besar intensitas serapan inframerah dari komposit dengan berbagai variasi kation. Terjadi perbedaan secara keseluruhan pada wilayah serapan inframerah, dimana wilayah serapan komposit Alginat/Zeolit/Zn (garis biru) lebih lemah dibanding serapan komposit Alginat/Zeolit/Fe (garis merah) dan lebih lemah dibanding serapan komposit Alginat/Zeolit/Fe-Zn (garis merah), ini mengindikasikan interaksi kation $\mathrm{Zn}$ 
dalam komposit lebih lemah dibandingkan komposit lainnya. Hal ini juga mengambarkan bahwa ion $\mathrm{Zn}$ akan lebih mudah terlepas dibandingkan ion $\mathrm{Fe}$ dalam proses pemanfaatannya sebagai material pupuk.

\section{Kesimpulan}

Sintesis dan karakterisasi komposit alginat/zeolit/Fe-Zn telah berhasil dilakukan untuk mempelajari visual secara fisik yang membentuk perbedaan warna dari setiap komposit dan analisis gugus fungsi menggunakan spektrofotometer inframerah untuk mendapatkan pemahaman mengenai interaksi gugus-gugus fungsi yang terdapat didalam material penyusun dengan kation yang diembankan. Studi ini diharapkan memberikan gambaran mengenai kemampuan alginat dan zeolit sebagai pengemban kation (unsur hara) yang bermanfaat bagi tanaman sebagai pupuk.

\section{Ucapan Terimakasih}

Penulis mengucapkan terimakasih kepada Direktorat Penelitian dan Pengembangan Masyarakat, Universitas Islam Indonesia atas dukungan pendanaan pada penelitian ini.

\section{Daftar Pustaka}

Ali, A., Zafar, H., Zia, M., ul Haq, I., Phull, A.R., Ali, J.S., Hussain, A., 2016. Synthesis, characterization, applications, and challenges of iron oxide nanoparticles. Nanotechnol. Sci. Appl. 9, 49-67. https://doi.org/10.2147/NSA.S999 86

Cakmak, I., Kalayc1, M., Ekiz, H., Braun, H.J., Kılınç, Y., Yılmaz, A., 1999. Zinc deficiency as a practical problem in plant and human nutrition in Turkey: A NATOscience for stability project. Field Crops Res. 60, 175-188. https://doi.org/10.1016/S03784290(98)00139-7

Draget, K.I., Taylor, C., 2011. Chemical, physical and biological properties of alginates and their biomedical implications. Food Hydrocoll., Dietary Fibre and Bioactive Polysaccharides 25, 251-256. https://doi.org/10.1016/j.foodhyd.2 009.10.007

Hochmuth, G., 2011. Iron (Fe) Nutrition of Plants [WWW Document]. URL http://edis.ifas.ufl.edu/ss555 (accessed 2.1.18).

Morrissey, J., Guerinot, M.L., 2009. Iron uptake and transport in plants: The good, the bad, and the ionome. Chem. Rev. 109, 4553-4567. https://doi.org/10.1021/cr900112r

Nayak, P.L., Sahoo, D., 2011. Chitosanalginate composites blended with cloisite 30B as a novel drug delivery system for anticancer drug paclitaxel. Int. J. Plast. Technol. 15, 68-81. 
https://doi.org/10.1007/s12588-

011-9000-6

Pechar, F., Rykl, D., 1981. Infrared spectra of natural zeolites of the stilbite group. Chem. Pap. 35, 189-202.

Savci, S., 2012. Investigation of Effect of Chemical Fertilizers on Environment. APCBEE Procedia, International Conference on Environmental Science and Development (ICESD 2012), 5-7 January 2012, Hong Kong 1, $287-$ 292.

https://doi.org/10.1016/j.apcbee.20 12.03.047

Tsintskaladze, G., Eprikashvili, L., Urushadze, T., Kordzakhia, T., Sharashenidze, T., Zautashvili, M., Burjanadze, M., 2016.

Nanomodified natural zeolite as a fertilizer of prolonged activity. Ann. Agrar. Sci. 14, 163-168. https://doi.org/10.1016/j.aasci.201 6.05 .013

Völz, H.G., Kischkewitz, J., Woditsch, P., Westerhaus, A., Griebler, W.-D., De Liedekerke, M., Buxbaum, G., Printzen, H., Mansmann, M., Räde, D., Trenczek, G., Wilhelm, V., Schwarz, S., Wienand, H., Adel, J., Adrian, G., Brandt, K., Cork, W.B., Winkeler, H., Mayer, W., Schneider, K., Leitner, L., Kathrein, H., Schwab, E., Jakusch, H., Ohlinger, M., Veitch, R., Etzrodt, G., Pfaff, G., Franz, K.D., Emmert, R., Nitta, K., Besold, R., Gaedcke, H., 2000. Pigments, Inorganic, in: Ullmann's Encyclopedia of Industrial Chemistry. Wiley-VCH Verlag
GmbH \& Co. KGaA. https://doi.org/10.1002/14356007. a20_243.pub2 